\title{
Modelling eco-physiological response of table olive trees (Olea europaea L.) to soil water deficit conditions
}

\author{
Giovanni Rallo*, Giuseppe Provenzano \\ Dipartimento dei Sistemi Agro-Ambientali (SAgA), Università degli Studi, Viale delle Scienze 12, Palermo, Italy
}

\section{A R T I C L E I N F O}

Article history:

Available online 8 November 2012

\section{Keywords:}

Water stress functions

Sap flow

Leaf/stem water potentials

\begin{abstract}
A B S T R A C T
The knowledge of crop response to water stress is crucial to predict transpiration reductions under limited soil water conditions and for a rational scheduling of irrigation.

In order to assess whatever water stress model, it is necessary to estimate critical thresholds of soil water status, below which plant transpiration starts to decrease.

The main objective of the work is to identify the shape and to determine the parameters of table olive orchards (Olea europaea, var. Nocellara del Belice) water stress function, assessed according to relative transpiration or leaf/stem water potential.

In order to assess different water stress functions describing the eco-physiological field response to soil water status, an experimental campaign was carried out in a farm located in South-West coast of Sicily. Meteorological data and soil and crop water status were monitored during irrigation seasons 2008 and 2009.

A value of soil matric potential of about $-40 \mathrm{~m}$ was identified as the threshold below which actual transpiration decreases with decreasing soil water content. For values of soil matric potential higher than the critical threshold, actual transpiration resulted almost constant. A similar behavior was observed when the xylematic leaf/stem water potentials were used to quantify the crop water stress. Investigation also showed that the non-linear models better reproduced the initial phase of the transpiration reduction process; for the examined crop, in fact, convex shape models, typical of xerophytes, better reproduce the reductions of actual transpiration under the soil water deficit conditions recognized in the field.
\end{abstract}

(C) 2012 Elsevier B.V. All rights reserved.

\section{Introduction}

Table Olive varieties play an important role in the agricultural and processing sectors of the Mediterranean countries. In the past, olive orchards were mostly rain fed, due to their resilience to water scarcity. The practice of irrigation is relatively new; it has been introduced in order to increase significantly the crop productions and to improve the yield quality (Patumi et al., 2002; D’Andria et al., 2004).

Several researches have been focusing on the optimization of irrigation for olive trees (Rousseaux et al., 2009; Fernández et al., 2006; Tognetti et al., 2004) and it has been recognized how, maintaining olive trees under slight or moderate water stress at specific phenological stages, can contribute to optimize the crop productivity and water use efficiency (Patumi et al., 1999; Berenguer et al., 2006; Caruso et al., 2011).

Impact of water stress as well as its feasible duration and intensity, in fact, depends on crop phenological stages in which the

\footnotetext{
* Corresponding author.

E-mail address: rallo.giovanni@gmail.com (G. Rallo).
}

stress occurs. Defining irrigation doses and timing under slight or moderate water stress levels, requires to monitor the water status in the soil-crop system and to identify affordable indicators, able to provide suggestions for irrigation scheduling aimed to achieve desired outcomes.

Soil-plant-atmosphere (SPA) water exchanges can be assessed by direct measurements of soil water content, plant water status and environmental variables that, linked to mathematical models, can allow to identify the complex interactions across the SPA continuum (Minacapilli et al., 2008; Cammalleri et al., 2010a).

Estimation of actual evapotranspiration can be obtained using soil water balance and/or energy balance approaches (Minacapilli et al., 2009; Cammalleri et al., 2010b; Rallo et al., 2012). With these approaches it is possible to consider the existence of plant water stress through the reductions of root water uptake and/or flux transpiration, both representing the natural response of plant to soil water deficit. Such reductions are usually schematized by means of a linear function.

Two approaches have been proposed to evaluate the crop transpiration: the "microscopic approach" considering the water movement toward and into individual roots (Personne et al., 2003) and the "macroscopic approach" in which a sink-term represents 
the water extraction by plant roots (Skaggs et al., 2006). Because the first approach requires a detailed knowledge of the root characteristics, quite difficult to determine, the latter is generally preferred for practical applications.

The macroscopic approach considers global stress indicators (relative transpiration, xylematic water potential, etc.), without regarding the flow patterns toward individual roots, and avoiding the need of analyzing the potential gradients distribution in the soil-roots interface. Using this approach it is possible to assess empirical functions able to describe the plant response to water stress, on the basis of parameters dependent on the soil or crop water status.

Actual transpiration fluxes can be therefore determined multiplying the maximum crop transpiration for a water stress coefficient, depending on the soil/plant water status and on environmental variables.

Several models have been proposed to quantify the water stress coefficient as linear or nonlinear functions of the soil water status, expressed in terms of matric potential (Feddes et al., 1978; van Genuchten, 1987; Dirksen et al., 1993; Homaee, 1999) or soil water depletion (Steduto et al., 2009).

For a certain crop the water stress function can be defined once it is known its shape and the thresholds values of soil water content or matric potential representing, from one side, the soil water status beyond which crop water stress occurs and, from the other, the condition of maximum stress.

With reference to the critical thresholds of soil water status on olive orchards, Fernández and Moreno (1999) observed the absence of crop water stress in the range of the available water between 1 and 0.4 . This condition was recognized according to values of pre-dawn xylematic and stems water potential around $-0.46 \mathrm{MPa}$ and $-1.3 \mathrm{MPa}$ respectively. In the same experiments, the maximum water stress condition was determined as corresponding to soil matric potentials lower than $-1.5 \mathrm{MPa}$, usually considered as wilting point for other fruit tree species.

Even if various linear and nonlinear water stress functions have been proposed for different crops (Ahuja et al., 2008), there is a lack of knowledge on the shape of the water stress function valid for olive orchards, so that field specific investigations are required.

In this context, the main objective of the work is to assess the shape of the water stress function for table olive orchards. Such function has been expressed as a relationship between the relative transpiration and the soil water status identified according to soil matric potential or, alternatively, between the leaf/stem water potential and the relative depletion.

Finally, critical thresholds of soil water status, identified according to measured soil matric potentials and leaf/stem xylematic potentials, were used to determine the water stress functions parameters.

\subsection{Modelling plant water stress response}

Under water stress conditions, olive plants develop different adaptive strategies: (i) reducing the water content/xylematic potential of its tissues, in order to increase the gradient of potential between soil and leaves; (ii) limiting the plant grow without stopping its photosynthetic activity; (iii) adjusting the osmotic potential, so that the cellular turgor and the leaf activities are maintained (Xiloyannis et al., 1999).

Despite the complexity of the olive response to soil water deficit, the spatial distributions of roots and soil water content play an important role on stomatal conductance and air leaf water status. These circumstances suggest the use of the macroscopic approach to assess the water stress function as a reduction term, $\alpha$, of potential transpiration, defined as:

$\alpha=\frac{T_{a}}{T_{p}}$

where $T_{a}$ and $T_{p}$ are actual and potential transpiration. Once the potential transpiration is determined, the knowledge of $\alpha$ allows the estimation of actual transpiration $T_{a}$.

Potential transpiration, $T_{p}$, can be estimated by following the procedure suggested by Jarvis and Mc Naughton (1986):

$T_{p}=\frac{\Delta R+\rho C_{p} V P D / r_{a}}{\lambda\left[\Delta+\gamma\left(r_{a}+r_{c, \min } / r_{a}\right)\right]}$

where $\Delta\left[\mathrm{kPaC}^{-1}\right]$ is the slope of the saturation vapor pressure curve, $R\left[\mathrm{~W} \mathrm{~m}{ }^{-2}\right]$ is the net radiation, $\rho\left[\mathrm{kg} \mathrm{m}^{-3}\right]$ is the air density, $C_{p}\left[\mathrm{~J} \mathrm{~kg}^{-1} \mathrm{~K}^{-1}\right]$ the air specific heat at constant pressure, $\gamma\left[\mathrm{kPa} \mathrm{K}^{-1}\right]$ is the psychometric constant, VPD [kPa] is the air vapor pressure deficit, $\lambda\left[\mathrm{J} \mathrm{kg}^{-1}\right]$ is the latent heat of vaporization, $r_{a}$ and $r_{c \text {,min }}$ are the aerodynamic and the minimum canopy resistance, respectively.

All the variables in Eq. (2) can be obtained from recorded meteorological data, except $r_{a}$ and $r_{c}$, requiring more complicated computations.

Assuming a logarithmic wind profile, the aerodynamic resistance, $r_{a}\left[\mathrm{~s} \mathrm{~m}^{-1}\right]$, for neutral conditions, can be evaluated with an expression derived from turbulent transfer, (Perrier, 1975):

$r_{a}=\frac{\ln \left[(z-d) / z_{o m}\right] \ln \left[(z-d) /\left(h_{c}-d\right)\right]}{k^{2} u_{z}}$

where $z[\mathrm{~m}]$ is the reference level at which the wind speed $u_{z}$ [ $\left.\mathrm{m} \mathrm{s}^{-1}\right]$ is measured and $z_{\text {om }}=0.123 h_{c}[\mathrm{~m}]$ is the roughness length for momentum, $h_{c}[\mathrm{~m}]$ is crop height, $k(=0.41)$ is the von Karman's constant equal to $0.41, d=0.667 h_{c}[\mathrm{~m}]$ is the zero plane displacement height.

On the other hand, values of $r_{c}$ can be obtained by means of a physically-based approach, as (Berni et al., 2009):

$r_{c}=\frac{r_{a}\left(e_{c}^{*}-e_{a}\right)}{\gamma\left[r_{a} R / \rho c_{p}-\left(T_{c}-T_{a}\right)\right]}-r_{a}$

where $e_{c}{ }^{*}$ is the saturated vapor pressure at the canopy temperature, $T_{c}$, and $e_{a}$ is the actual vapor pressure.

A rather simple approach to evaluate $\alpha$ as a function of soil water pressure head, has been proposed by Feddes et al. (1978):

$\alpha(h)=\frac{h-h_{4}}{h^{*}-h_{4}}$

where $h^{*}$ is a threshold value of the matric potential depending on the transpirative atmospheric demand and $h_{4}$ is the matric potential corresponding to the wilting point. This model describes the water stress through a linear function, so that the actual transpiration linearly decreases with $\alpha$, in the range $h_{4}<h<h^{*}$.

The shape of transpiration reduction function depends on several factors and in particular on the eco-physiological processes, like plant resistance/tolerance/avoidance to water stress (Larcher, 1995), as well as on soil water availability and spatial distribution in the root zone (Guswa et al., 2004).

Convex $\alpha(h)$ curves are typical of xerophytes, for which the reductions of actual transpiration becomes severe only for extreme water stress. On the other hand, concave shapes of the $\alpha(h)$ relationship, denote strong reductions of actual transpiration, even for slight stress levels.

The shape of the stress function can be taken into account by introducing an exponent, $a$, to the right side member of Eq. (5):

$\alpha(h)=\left(\frac{h-h_{4}}{h^{*}-h_{4}}\right)^{a}$ 
Values of $0<a<1$ define convex shapes, whereas values of $a>1$ reproduce concave shapes.

Another non-linear $\alpha(h)$ model was proposed by van Genuchten (1987):

$\alpha(h)=\frac{1}{1+\left(h / h_{50}\right)^{p}}$

where $h_{50}$ is the soil matric potential for which $\alpha=0.5$ and $p$ is a dimensionless parameter depending on crop, soil, and climate (Homaee, 1999).

Dirksen et al. (1993) modified Eq. (7), in order to assume that root water uptake decreases when soil matric potentials is lower than a threshold value $h^{*}$ :

$\alpha(h)=\frac{1}{1+\left[\left(h^{*}-h\right) /\left(h^{*}-h_{50}\right)\right]^{p}}$

Homaee (1999) replaced, in Eq. (8), $h_{50}$, with $h_{\max }$, to take into account the soil matric potential beyond which the changes of $h$ no longer significantly influence the relative transpiration and introduced a second parameter, $\alpha_{0}$, representing the relative transpiration at $h_{\max }$, so that:

$\alpha(h)=\frac{1}{1+\left(1-\alpha_{0}\right) / \alpha_{0}\left[\left(h^{*}-h\right) /\left(h^{*}-h_{\max }\right)\right]^{p}}$

Recently, Steduto et al. (2009) proposed a new model, describing the stress coefficient, $\alpha$, as a function of the relative depletion $\left(D_{\text {rel }}\right)$, defined in the domain of soil water contents determining stress conditions for the $\operatorname{crop}\left(\theta^{*}<\theta<\theta_{\min }\right)$ :

$\alpha\left(D_{\text {rel }}\right)=1-\frac{e^{D_{\text {rel }} f_{s}}-1}{e^{f_{s}}-1}$

where $f_{s}$ is a parameter defining the shape of the stress function. This function is linear for $f_{s}$ tending to 0 , concave for $f_{s}<0$, and convex for $f_{s}>0$.

The relative depletion can be evaluated as:

$D_{\text {rel }}=\frac{\theta^{*}-\theta}{\theta^{*}-\theta_{\min }}$

where $\theta^{*}$ is the threshold value of the soil water content below which water stress occurs and $\theta_{\min }$ corresponds to the soil water content for which the stress is at its full strength.

According to Eq. (11), water stress starts when $D_{\text {rel }}>0(\alpha<1)$; at the lowest water content $\left(\theta_{\min }\right)$, the effect of water stress is extreme $\left(D_{\text {rel }}=1 ; \alpha=0\right)$.

For each value of the relative depletion, the stress coefficient $\alpha$ can be evaluated in terms of leaf/steam water potentials or stomatal conductance (Raes, 2008). Whatever eco-physiological variable is used, it is necessary to normalize its measured value to a fractional scale variable in the range $0-1$.

Considering that all the described stress functions are empirical, the upper and lower thresholds of soil/crop water status must be locally determined, in order to take into account the crop, the climate and the soil properties. Moreover, for each soil-crop system the parameters of the stress functions must be determined.

\section{Materials and methods}

\subsection{Site descriptions and experimental layout}

Experiments were carried out during irrigation seasons 2008 and 2009 (from June to September), in the farm "Tenuta Rocchetta" located near Castelvetrano (TP), in SW of Sicily (Lat. $37^{\circ} 38^{\prime} 36.8^{\prime \prime}$, Long. $12^{\circ} 50^{\prime} 49.8^{\prime \prime}$ ).

The farm, having an extension of about 13 ha, is mostly cultivated with table olive grove (Olea europaea L., var. Nocellara del
Belice), representing the main crop in the surrounding area. The experimental plot is characterized by 15 years old olive trees, planted on a regular grid of $8 \times 5 \mathrm{~m}$ ( 250 plants/ha); the mean canopy height is about $3.7 \mathrm{~m}$ and the average fraction of vegetation cover is about 0.35 . Irrigation is practiced by means of a drip irrigation system, with four $81 / \mathrm{h}$ emitters per plant. Soil texture was measured using the hydrometer method on the same soil samples used for the water retention curves. Soil textural class, according USDA classification, is silty clay loam.

Standard meteorological data (incoming short-wave solar radiation, air temperature, air humidity, wind speed and rainfall) were hourly collected by SIAS (Servizio Informativo Agrometeorologico Siciliano), with standard equipments installed about $500 \mathrm{~m}$ apart from the experimental field. Net radiation $R$ and its components were measured with a 4-component net radiatiometer (NR01, Hukeseflux). According to ASCE-ESRI, the standardized Penman-Monteith method (Allen et al., 2005) was used to calculate atmospheric water demand.

A preliminary investigation on the root spatial distribution was carried out in order to identify the soil volume with the highest root density, where the water uptake processes are concentrated. Vertical and horizontal root length density (RDL) were determined on sixteen vertical profiles opened according to a regular grid, where 96 soil carrots ( $5 \mathrm{~cm}$ diameter and $15 \mathrm{~cm}$ high) were collected at depths of 30,45, 60, 75, 90 and $100 \mathrm{~cm}$. Root extraction procedure followed the protocol proposed by Newman (1966). Fig. 1 shows, per each investigated layer, a 2D map of the normalized RDL values. As can be observed at each depth the highest root density is localized in the soil volume wetted with irrigation.

Investigation allowed to identify two soil volume explored by roots (Xiloyannis et al., 2012): the first where most of the root absorption takes place, corresponds to the soil volume wetted during irrigation, whereas the second volume, also explored by roots, is not wetted during irrigation. According to the experimental results the soil volume where $80 \%$ of roots are localized, can be assumed as a parallelepiped with a length equal to the tree spacing $(5.0 \mathrm{~m})$, a width of $1.5 \mathrm{~m}$ and a depth of $0.75 \mathrm{~m}$.

Soil water retention curves were determined on eight undisturbed soil samples, $0.08 \mathrm{~m}$ diameter and $0.05 \mathrm{~m}$ height, collected at depth of $0,30,60$ and $100 \mathrm{~cm}$, inside the soil volume where $80 \%$ of roots are localized. Hanging water column apparatus (Burke et al., 1986) was used to evaluate soil water contents corresponding to $h$ values ranging from -0.05 to $-1.5 \mathrm{~m}$; pressure plate apparatus (Dane and Hopman, 2002), with sieved soil samples $0.05 \mathrm{~m}$ diameter and $0.01 \mathrm{~m}$ height, was used to determine soil water contents corresponding to $h$ values of $-3.37 \mathrm{~m},-10.2 \mathrm{~m},-30.6 \mathrm{~m}$, and $-153.0 \mathrm{~m}$. For each undisturbed sample dry bulk density, $\rho_{b}$, $\left[\mathrm{Mg} \mathrm{m}^{-3}\right]$ was also determined.

The van Genuchten model (van Genuchten, 1980) was used to fit experimental data; the water retention curve parameters were obtained by means of the retention code, RETC (van Genuchten et al., 1992).

Fig. 2 shows the soil water retention curves obtained for the investigated layers, whose van Genuchten parameters are shown in Table 1. Considered the low differences between soil water contents measured at the different layers, for each fixed matric potential, an averaged soil water retention curve was used for the following analysis.

Irrigation scheduling followed the ordinary management practised in the surrounding area. The total irrigation depth provided by the farmer was equal to $122 \mathrm{~mm}$, divided in four waterings, in 2008 and $127 \mathrm{~mm}$, divided in five waterings, in 2009. Table 2 shows the irrigation calendar and the rainfall depths during the investigation periods, from July, 1, 2008 to August, 31 of 2008 and 2009.

In order to evaluate the water stress thresholds and to estimate the model fitting parameters at the scale of a single plant, 


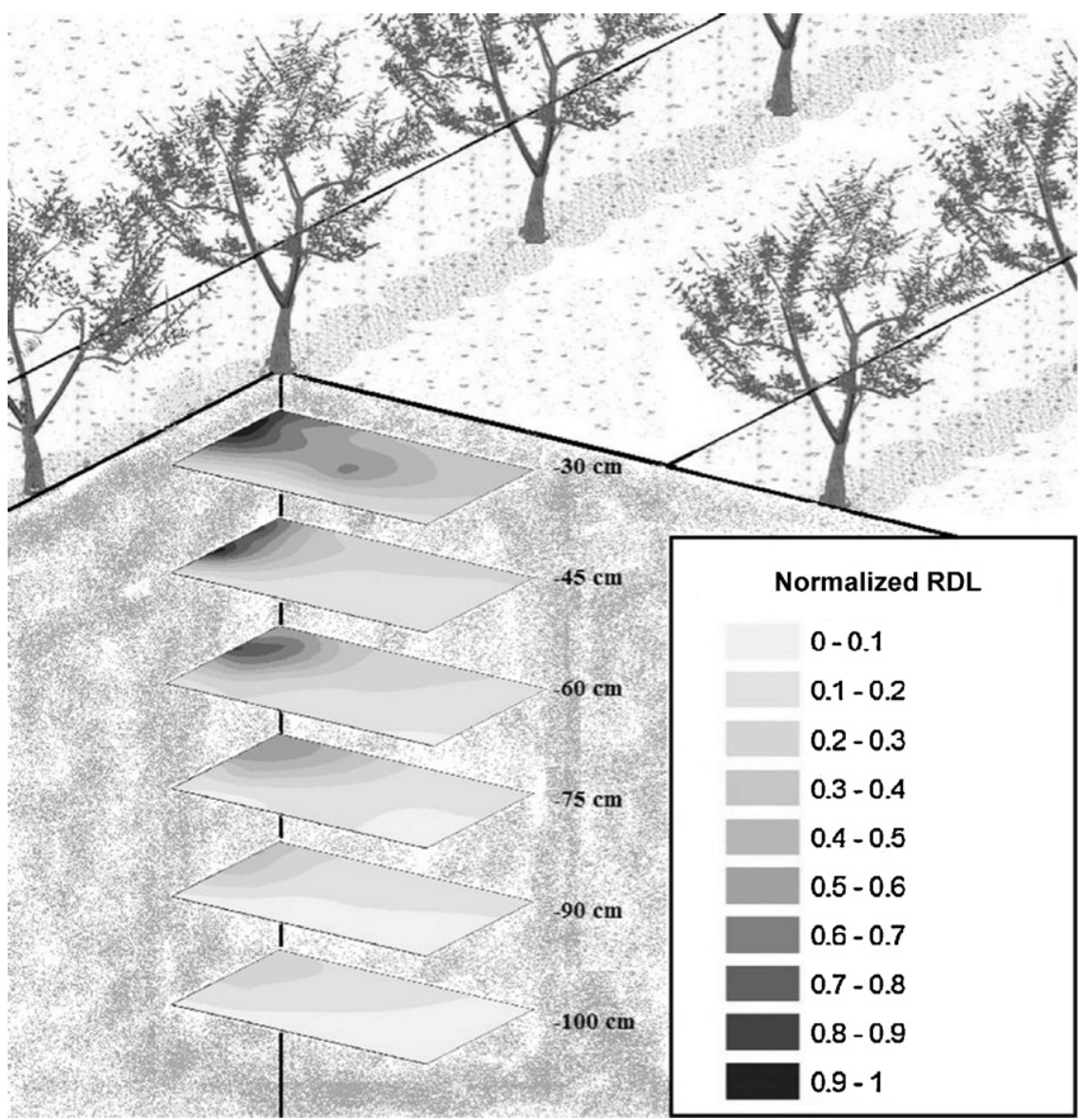

Fig. 1. 2D maps of the root length density distribution at different soil layers from 0 to $100 \mathrm{~cm}$.

\section{Table 1}

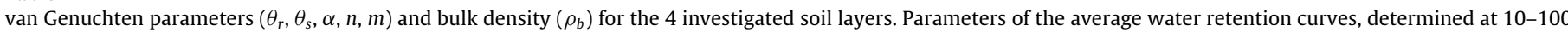
and $45-65 \mathrm{~cm}$, are also showed. $\theta_{r}=$ residual soil water content; $\theta_{s}=$ saturated soil water content; $\alpha, n, m$ : fitting parameters .

\begin{tabular}{|c|c|c|c|c|c|c|}
\hline Depth $(\mathrm{cm})$ & $\theta_{s}\left(\mathrm{~cm}^{3} \mathrm{~cm}^{-3}\right)$ & $\theta_{r}\left(\mathrm{~cm}^{3} \mathrm{~cm}^{-3}\right)$ & $\alpha\left(\mathrm{cm}^{-1}\right)$ & $n(-)$ & $m(-)$ & $\rho_{b}\left(\mathrm{Mg} \mathrm{m}^{-3}\right)$ \\
\hline 0 & 0.39 & 0.05 & 0.008 & 1.32 & 0.24 & 1.36 \\
\hline 30 & 0.56 & 0.05 & 0.015 & 1.19 & 0.16 & 1.31 \\
\hline 60 & 0.39 & 0.06 & 0.014 & 1.23 & 0.18 & 1.38 \\
\hline 100 & 0.36 & 0.06 & 0.022 & 1.18 & 0.15 & 1.61 \\
\hline Average $10-100 \mathrm{~cm}$ & 0.42 & 0.05 & 0.015 & 1.23 & 0.18 & 1.41 \\
\hline Average $45-65 \mathrm{~cm}$ & 0.47 & 0.05 & 0.014 & 1.21 & 0.17 & 1.34 \\
\hline
\end{tabular}

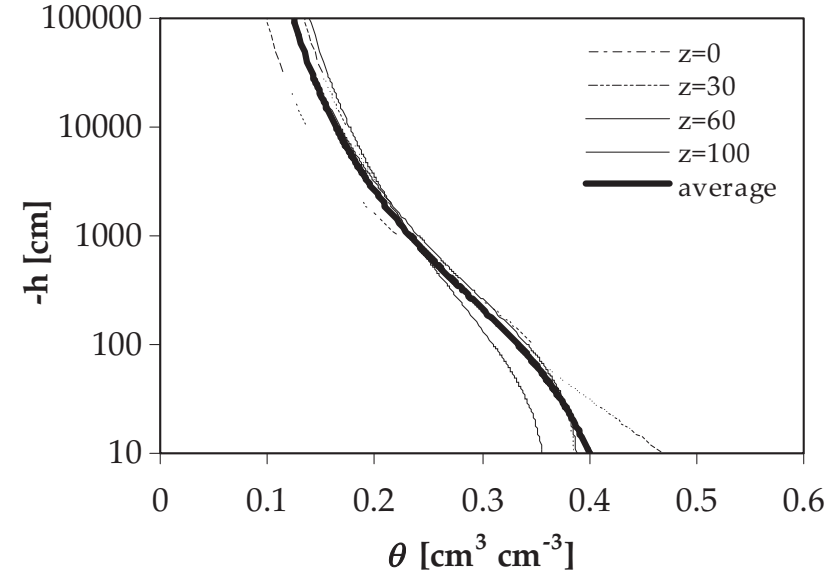

Fig. 2. Soil water retention curves for the four investigated layers and average curve for the entire soil profile. Soil water retention curves were determined on eight undisturbed soil samples, collected into soil volume where most of the root absorption takes place.
Table 2

Irrigation scheduling and rainfall depth in the period from July 1 to August 31, 2008 and 2009.

\begin{tabular}{lcc}
\hline Data & Irrigation depth $(\mathrm{mm})$ & Rainfall depth $(\mathrm{mm})$ \\
\hline 12-July-2008 & 30.6 & 0.6 \\
30-July-2008 & 30.6 & \\
12-August-2008 & 30.6 & \\
13-August-2008 & 30.6 & 12.6 \\
14-August-2008 & & 12.6 \\
26-August-2008 & 122.4 & \\
Total 2008 & 5.1 & \\
13-July-2009 & 30.6 & \\
5-August-2009 & 30.6 & \\
6-August-2009 & 30.6 & \\
7-August-2009 & 17.8 & \\
19-August-2009 & 12.7 & 5.2 \\
20-August-2009 & & 5.2 \\
21-August-2009 & & 10.4 \\
26-August-2009 & 127.4 & \\
Total 2009 & & \\
\hline
\end{tabular}


experiments were carried out by monitoring, during a dry period, the evolution of the considered water stress coefficients, $\alpha(h)$ or $\alpha\left(D_{\text {rel }}\right)$, and the corresponding soil water status, described in terms of $h$ or $D_{\text {rel }}$.

\subsection{Measurements of soil and plant water status}

Spatial and temporal variability of soil water contents was monitored, from the soil surface to a depth of $100 \mathrm{~cm}$, using a Diviner 2000 Sentek FDR (Frequency Domain Reflectometry) probe. The access tubes have been placed in the soil volume where $80 \%$ of roots were localized. The probe was initially calibrated in order to determine a site specific relationship between the measured Scaled Frequency, SF, and the volumetric soil water content, $\theta$.

Five access tubes were installed along the direction of the irrigation pipeline, between two consecutive trees and where the highest change of soil water content occurred. In this way it was possible to take into account the spatial variability of soil water content after irrigation. Soil water contents measurement were carried out every five days, as well as before and after each watering.

In 2009 season, additional measurements of soil water contents were carried out using TDR (Time Domain Reflectometry) probes connected to a multiplexer. Six probes, $20 \mathrm{~cm}$ length, were installed between two consecutive trees along the direction of the irrigation pipeline, at distances of 50,100 and $250 \mathrm{~cm}$ from the tree, in the layer 5-25 $\mathrm{cm}$ and $40-60 \mathrm{~cm}$.

Values of soil water contents measured with FDR and TDR systems were then averaged proportionally to the spatial root density experimentally measured, in order to determine, for each measurement day, a single value of $\theta$, representative of the soil layer where most of the root absorption takes place.

For each soil water content, $\theta$, the relative depletion can be determined with Eq. (11), once the threshold values of the soil water content, $\theta^{*}$ and $\theta_{\min }$, are known.

Sap fluxes were measured hourly, on three olive trees, by thermal-based sensors, using two standard Thermal Dissipation Probes, TDPs (Granier, 1987) per each tree. As suggested by the manufacturer, the probes were implanted $22 \mathrm{~cm}$ deep, in order to sample only the conductive area. After installing the probes, the trunk was wrapped in reflective insulation. Each hour the temperature difference between the heated upper needle and the un-heated lower needle, combined with the temperature difference at night allowed to estimate the sap velocity, that was then multiplied to the sapwood area in order to obtained hourly sap fluxes.

At the end of the experiments, the sapwood area was determined by a colorimetric method, on a total of six wood carrots extracted on the same three trees, in between each couple of the sap flow probes, with a Pressler gimlet. The conductive section was identified by adding methyl-orange to the carrot, in order to enhance the difference between the sapwood and the heartwood. Each image of colored wood carrot was then analyzed with software Image-Pro Plus 6.0 to recognize the sapwood depth. The fluxes were then integrated on a daily scale in order to evaluate the volume of water consumed by each plant.

The actual daily stand transpiration, $T_{a}\left(\mathrm{mmd}^{-1}\right)$, was then obtained by scaling up the sap fluxes taking into account the pertinence area of a single plant $\left(40 \mathrm{~m}^{2}\right)$, under the hypotheses of neglecting, at a daily scale, the tree capacitance.

In order to estimate $T_{p}$ by means Eq. (2), values of net radiation $R$ were continuously monitored with a 4-component net-radiometer (NR-01, Hukseflux ${ }^{\mathrm{TM}}$ Thermal Sensors), installed 6 m apart from the investigated trees. The minimum value of the canopy resistance, $r_{c \text {,min }}$, has been calculated applying Eq. (4) through measurement of canopy temperature at midday, with a hand held infrared thermometer, carried out on 3 additional fully irrigated olive plants. In order to reduce the possible direct soil thermal effect, for each tree, 6 values of canopy temperature were randomly acquired by the side of the cardinal directions.

A number of two replicates of predawn leaf water potential, (PLWP), midday leaf water potential (MLWP) and midday stem water potential (MSWP) were measured by using a pressure chamber (Scholander et al., 1965) with the protocol proposed by Turner and Jarvis (1982), in the same three trees, where soil water status and sap fluxes were monitored. In particular, PLWP measures the plant water status at theoretical (or nominal) zero plant water flux and provides information on soil water potential in the root zone as a consequence of the equilibrium between soil and atmosphere. MLWP, measured on a single leaf, reflects the combination of local factors like leaf water demand, vapor pressure deficit (VPD), leaf intercepted radiation, soil water availability, internal plant hydraulic conductivity and stomatal regulation, whereas MSWP, measured on a non-transpiring steam (Begg and Turner, 1970) mainly depends on the soil water status.

For each tree, the values of leaf water potentials were measured on one-year-old shoots, whereas MSWPs were measured on leaves that were covered with foil faced bags, after at least $30 \mathrm{~min}$ prior to measurements to allow equilibration. Measurements were carried out every five days, as well as during the days immediately before and after irrigation.

\section{Results and discussions}

A preliminarily investigation was carried out in order to proceed to the site-specific calibration of the FDR sensor and the following function was in particular obtained for the investigated soil site $\left(R^{2}=0.92 ;\right.$ RMSE $\left.=0.03 \mathrm{~cm}^{3} \mathrm{~cm}^{-3}\right)$ :

$\theta=38.225 \mathrm{SF}^{3.4918}$

In order to give a general overview about the environmental variables, Fig. 3a-f shows, for 2008 and 2009, the daily dynamic of standard meteorological variables as well as the reference evapotranspiration.

The thermal measurements performed over well watered plants allowed to estimate the minimum value of the canopy resistance, $r_{c, \text { min }}\left[\mathrm{s}^{-1} \mathrm{~mm}\right]$, necessary to compute the potential transpiration, $T_{p}$. For the considered periods, the average minimum value of canopy resistance, $r_{c, \min }$, evaluated with Eq. (4), resulted equal to $76 \pm 5 \mathrm{~s} \mathrm{~m}^{-1}$.

For the constantly irrigated plants, Table 3 shows the minimum and maximum values of the meteorological variables, as well as of soil water content, predawn leaf water potential and canopy temperature, recorded during the investigated periods. According to the PLWP threshold values suggested by Fernández and Moreno (1999), the monitored plants were practically maintained under conditions of absence or moderate water stress (PLWP $\leq 0.5 \mathrm{MPa}$ ).

\section{Table 3}

Maximum and minimum hourly values of collected environmental variables for well watered trees, used to estimate the minimum canopy resistance.

\begin{tabular}{lcc}
\hline Variable & Value & \\
\cline { 2 - 3 } & Max & Min \\
\hline Air temperature $\left({ }^{\circ} \mathrm{C}\right)$ & 39.7 & 25.4 \\
Air relative humidity $(\%)$ & 69.0 & 16.0 \\
Vapor pressure deficit $(\mathrm{kPa})$ & 5.4 & 1.2 \\
Wind velocity at $10 \mathrm{~m}\left(\mathrm{~m} \mathrm{~s}^{-1}\right)$ & 5.4 & 1.1 \\
\left. Wind velocity at $2{\mathrm{~m}\left(\mathrm{~m} \mathrm{~s}^{-1}\right)}^{-2}\right)$ & 3.3 & 0.7 \\
Solar radiation $\left.(\mathrm{W} \mathrm{m})^{-2}\right)$ & 949.5 & 53.8 \\
Net solar radiation $\left(\mathrm{W} \mathrm{m}{ }^{-2}\right)$ & 720.7 & 38.5 \\
Soil water content $($ vol.\%) & 44.0 & -0.50 \\
Predawn leaf water potential $(\mathrm{MPa})$ & -0.36 & 23.5 \\
Canopy temperature $\left({ }^{\circ} \mathrm{C}\right)$ & 38.2 & \\
\hline
\end{tabular}



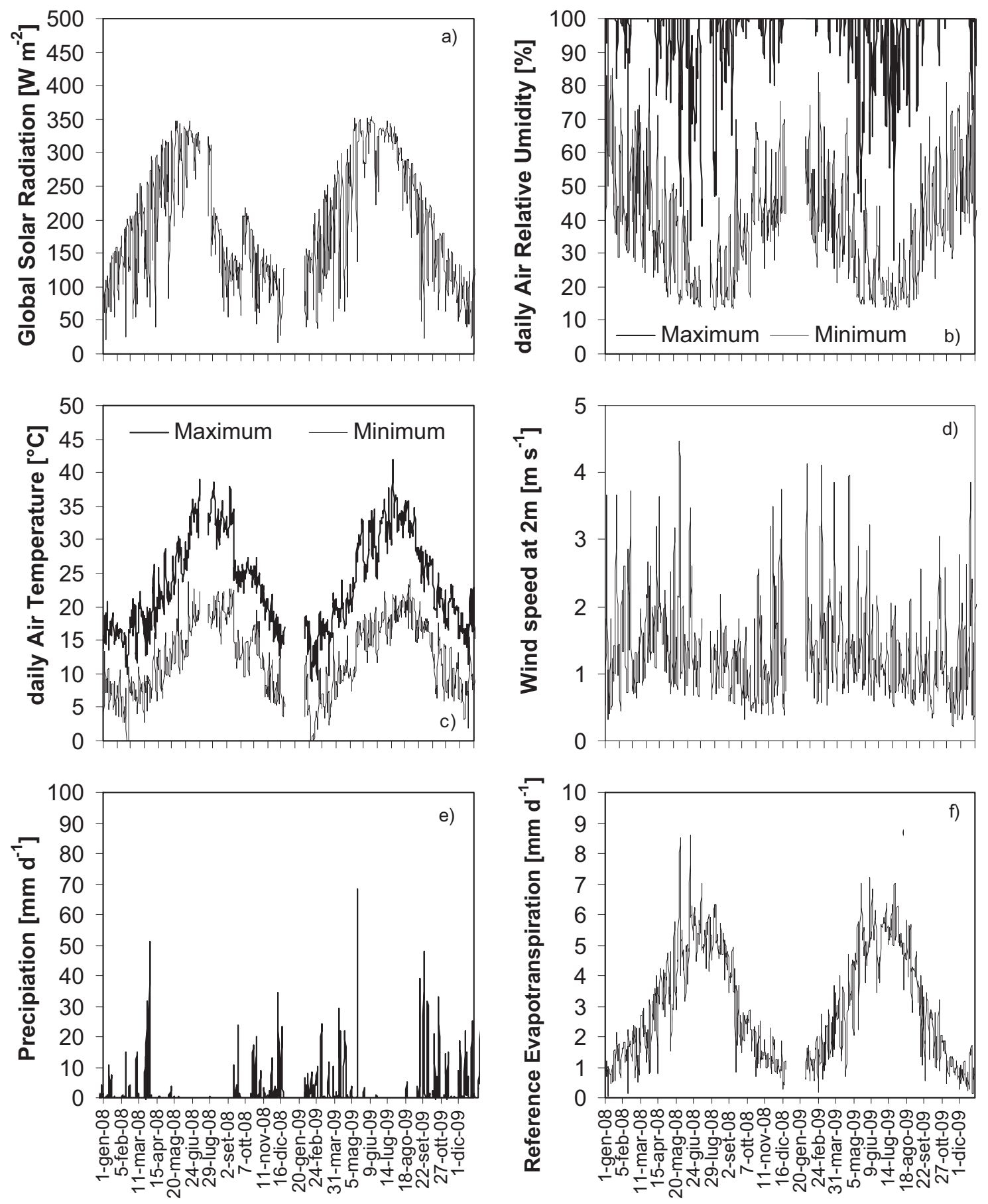

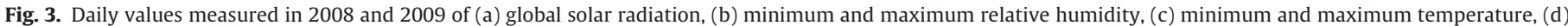
wind speed, (e) precipitation and (f) reference evapotranspiration.

\subsection{Plant-soil-water relationships and definition of critical thresholds}

Fig. 4 illustrates the actual transpiration, $T_{a}$, and the corresponding absolute values of PLWP, MLWP and MSWP. As can be observed actual transpiration is strongly correlated with all the considered independent variables. Moreover a decreasing trend of actual transpiration is evident at increasing absolute values of leaf or stem water potential.

Considering the high correlations observed between $T_{a}$ and plant water status identified through the leaf water potentials, an analysis was carried out in order to find the critical soil water status conditions identifying the begin and the maximum crop water stress.

Soil water status was expressed in terms of volumetric soil water content, $\theta$, and soil matric potential, $h$. While the first variable gives site-specific indications, the second is associated to the capacity of soil to hold water and therefore it can be considered as a status variable for the investigated system.

Fig. 5 shows the values of actual transpiration as a function of the average soil water content measured in 2008 and 2009 with the FDR technique, in the layer $10-100 \mathrm{~cm}$. The figure also represents the average water retention curve. Despite the limited number of $T_{a}$ measurements corresponding to high water contents, values 


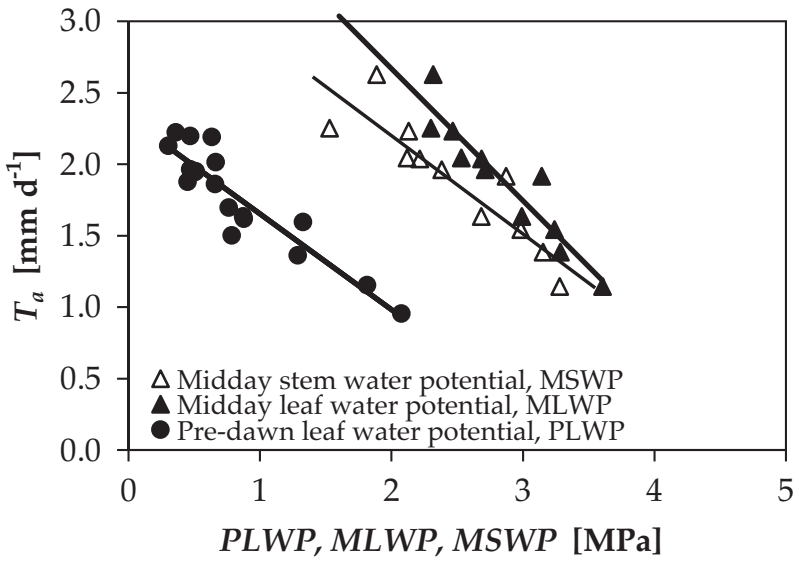

Fig. 4. Actual transpiration as a function of absolute values of predawn leaf water potential, PLWP, midday leaf water potential MLWP and midday stem water potential MSWP. Regression lines are also showed.

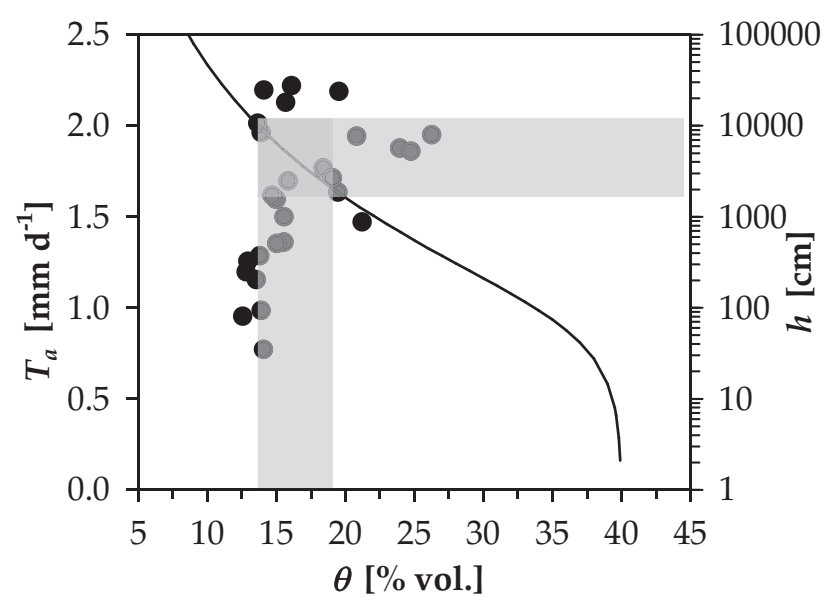

Fig. 5. Actual transpiration as a function of average soil water content in the layer $10-100 \mathrm{~cm}$. The average water retention curve, for the same layer, is also represented. Shaded area indicates the range of variation of the observed critical soil water status. of actual transpiration can be considered practically constant for soil water contents higher than a threshold value and drastically decreases for lower values. According to the experimental data, the critical average soil water content below which is recognizable a strong reduction of actual transpiration is approximately equal to $16 \pm 2 \%$. The variability of this threshold certainly depends on the atmospheric water demand.

The corresponding value of critical soil matric potential is around $40 \mathrm{~m}$, with values in the range $20-90 \mathrm{~m}$. This recognized large range is obviously consequent to the high change of soil matric potential corresponding to limited variations of soil water content. For soil water content higher than the critical value, actual transpiration is more or less constant and equal approximately to $2 \mathrm{~mm} \mathrm{~d}^{-1}$, whereas for lower water contents, actual transpiration drop off to a minimum value of about $0.7 \mathrm{~mm} \mathrm{~d}^{-1}$.

A similar trend is obtained when considering both FDR and TDR data in the layer $45-65$, where the highest root density is concentrated. Fig. 6 illustrates the values of actual transpiration as a function of the average soil water contents in the soil layer 45-65 cm, measured with both FDR and TDR techniques, the average water retention curve in the considered soil layer, as well as the range of variation of the observed critical thresholds of soil water content/matric potential.

Fig. 7a-c shows the experimental values of PLWP, MLWP, MSWP and the corresponding soil water contents, averaged for the root density, in the layer $10-100 \mathrm{~cm}$. As can be observed in Fig. 7a, the values of PLWP follow the same trend recognized for $T_{a}$.

Despite it was quite difficult to identify an unambiguous threshold of soil water content, due to the visible dispersion, the critical value of $\theta^{*} \approx 16 \%$ ( $h \approx 40 \mathrm{~m}$ ) previously obtained, was considered acceptable. The observed uncertainty could be due to xilematic potentials adjustment occurring when the plant is kept under soil water deficit for long time periods, as well as to the different climatic conditions recorded during the experiments.

The critical value $\theta^{*}$ separates two different plant behaviors: for $\theta>\theta^{*}$, the absolute values of PLWPs are constant and approximately equal to $0.5 \mathrm{MPa}$, identifying a condition of negligible water stress (Fernández and Moreno, 1999). On the other hands, for $\theta<\theta^{*}$, lower is the soil water content, smaller is the PLWP, as consequence of the progressively increasing water stress.

A similar threshold of soil water content can be obtained when MSWPs are considered in place of PLWPs. According to Fig. 7b, the detected threshold of $\theta^{*} \approx 16 \%(h \approx 40 \mathrm{~m})$ corresponds to MSWP

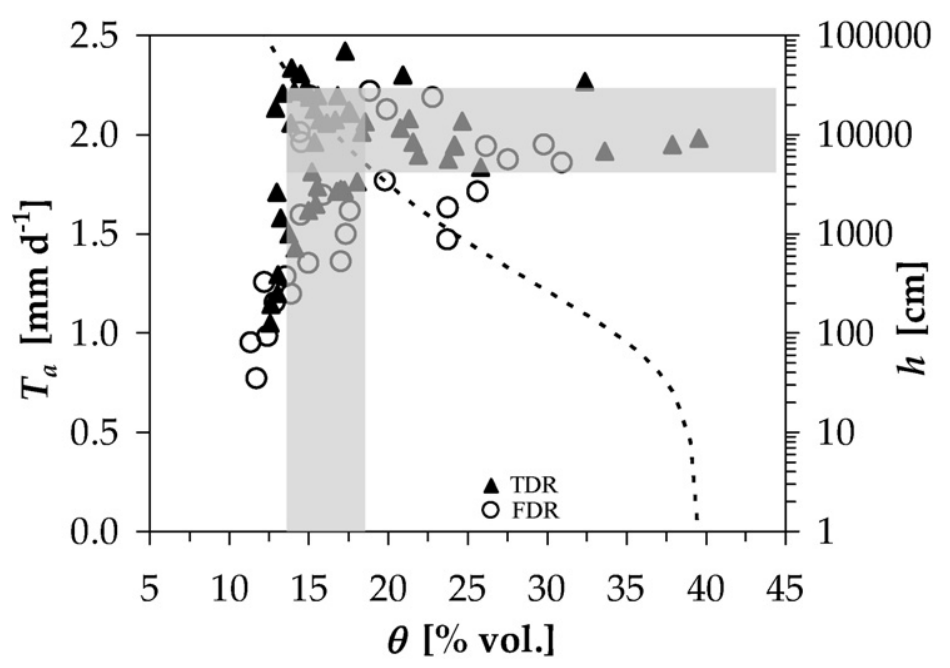

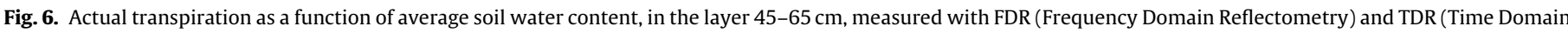

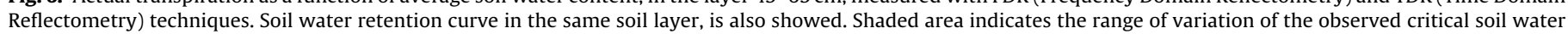
status. 

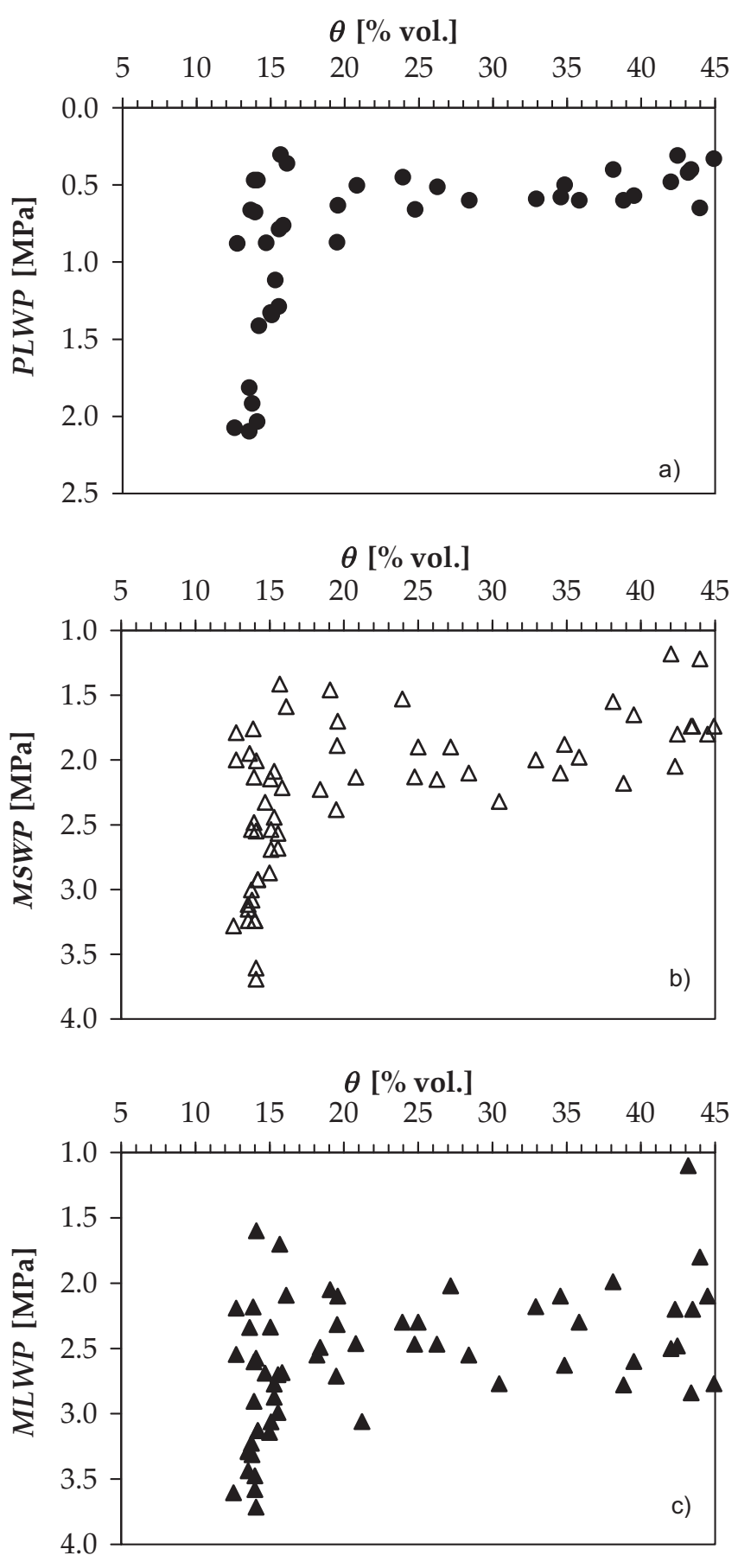

Fig. 7. (a-c) Experimental values of (a) predawn leaf water potential, PLWP, (b) midday leaf water potential MLWP (c) midday stem water potential MSWP and corresponding soil water contents in the layer $10-100 \mathrm{~cm}$.

around 1.7 MPa $(\mathrm{CV}=0.2)$. Despite the high variability of MSWP for fixed soil water content, the recognized threshold of MSWP is similar to the one proposed by Moriana et al., 2010, around 1.4 MPa, determined with measurements of Trunk Diameter Fluctuations (TDFs).

The higher dispersion observable for $\theta>\theta^{*}$, when MLWP or MSWP are considered in place of PLWP, can be explained by the dependence of the midday potentials from the environmental variables. However, under water stress conditions $\left(\theta<\theta^{*}\right)$, whatever potential is used, the dispersion is comparable as consequence of the minor influence of the environmental variables.
Experimental data represented in Fig. 7a-c provides also a clear identification of the soil water status corresponding to the maximum stress level recognized in the field. In fact, as can be observed in Fig. 7a, the maximum measured value of the PLWP equal to $2.1 \mathrm{MPa}$ corresponds to a soil water content slightly higher than $11 \%$ and consequently to a matric potential of about $h=200 \mathrm{~m}$. For the considered crop, a so high soil matric potential is a consequence of the high gradients of potential between the leaves and roots in drought periods, allowing the roots to extract water held with tension well below the traditionally accepted wilting point $(150 \mathrm{~m})$. Similar studies carried out by Xiloyannis et al. (1999) evidenced that the maximum stress condition correspond to matric potential of about $250 \mathrm{~m}$. However, for irrigation management, differences of matric potential between $150 \mathrm{~m}$ and $250 \mathrm{~m}$ do not produce significant changes in terms of soil water content and consequently on volumes of water to supply with irrigation.

The value of $h=200 \mathrm{~m}$ was assumed as the minimum thresholds of soil water status, identifying the most extreme water stress condition recognized in the field and corresponds to $h_{4}$, in Eqs. (5) and (6) or $h_{\max }$ in Eq. (9).

\subsection{Modelling olive response to soil water deficit}

According to the procedure proposed by Ewers and Oren (2000), to keep errors in $T_{p}$ to less than $10 \%$, estimated $T_{p}$ have to be limited to conditions for which $\mathrm{VPD} \geq 0.6 \mathrm{kPa}$. For this reason, it was therefore necessary to proceed to a data screening, in order to neglect all the environmental condition determining VPD $\geq 0.6 \mathrm{kPa}$.

Considering that the water stress conditions were observed in the range of soil matric potential absolute values between $40 \mathrm{~m}$ and $200 \mathrm{~m}$, the estimation of model parameters $\left(a, p, \alpha_{0}\right)$ was carried out by assuming that the first value is the threshold of soil matric potential $\left(h^{*}\right)$ below which the plant starts to reduce transpiration $\left(T_{a} T_{p}{ }^{-1}<1\right)$ whereas the second value was considered as the soil matric potential $\left(h_{4}\right.$ or $\left.h_{\max }\right)$ corresponding to the absence of transpiration. Moreover, considering that the minimum $\alpha$ observed in the field was equal to 0.6, the threshold $h_{50}$ in Eqs. (7) and (8), was assumed equal to $152 \mathrm{~m}$, corresponding to $\alpha=0.6$, rather than $\alpha=0.5$.

For all examined models, Table 4 shows the critical thresholds of soil water status as well as the relative parameters obtained by fitting the data with a least square method, by using the package Excelstat (Addinsoft USA, 2010) and the Pearson correlation coefficient.

Fig. 8a and b shows the $h, T_{a} T_{p}{ }^{-1}$ experimental data pairs as well as the fitting models (Eqs. (5)-(9)), whose critical thresholds and parameters are indicated in Table 4 . Analysis of data evidenced that non-linear water stress models, compared to the linear model, better reproduce the initial phase of the transpiration reduction process. The convex shape of the stress function evidences that water stress is more and more severe at increasing matric potential, and therefore the reduction of actual transpiration becomes critical only for the most extreme water stress conditions. For this reason, Feddes $\alpha(h)$ linear model, defined by only the measured critical thresholds of soil matric potential $\left(h^{*}, h_{4}\right)$, gives the worst result, because it does not allow to take into account the convex shape of the function.

Unfortunately, the absence of $T_{a} T_{p}{ }^{-1}$ measurements lower than 0.6 , does not permit to clearly choose the best shape under more severe water stress conditions than those observed. However under the examined field conditions it was very difficult to reach values of $T_{a} T_{p}{ }^{-1}$ lower than 0.6 , considering that: (i) the high capacitance characterizing the olive plants, like those observed, allows them a certain adaptation to water stress conditions; (ii) investigated soil is 
Table 4

Critical thresholds of soil water status and parameters of the examined models. Pearson correlation coefficient, $r$, and statistical significance are also showed.

\begin{tabular}{|c|c|c|c|c|c|c|c|c|}
\hline Eq. & Mathematical formulation & $h_{3}$ or $h^{*}(\mathrm{~m})$ & $h_{4}$ or $h_{\max }(\mathrm{m})$ & $h_{50}(\mathrm{~m})$ & $\alpha_{0}$ & $a$ & $p$ & $r$ \\
\hline 1 & $\alpha(h)=\frac{h-h_{4}}{h_{3}-h_{4}}$ & 40 & 200 & & & & & 0.63 (n.s.) \\
\hline 2 & $\alpha(h)=\left(\frac{h-h_{4}}{h_{3}-h_{4}}\right)^{a}$ & 40 & 200 & & & 0.34 & & $0.64(0.05)$ \\
\hline 3 & $\alpha(h)=\frac{1}{1+\left(h / h_{50}\right)^{p}}$ & & & 152 & & & 4.284 & $0.65(0.05)$ \\
\hline 4 & 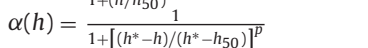 & 40 & & 152 & & & 3.137 & $0.66(0.05)$ \\
\hline 5 & $\alpha(h)=\frac{1}{1+\left(1-\alpha_{0}\right) / \alpha_{0}\left[\left(h^{*}-h\right) /\left(h^{*}-h_{\max }\right)\right]^{p}}$ & 40 & 200 & & 0.15 & & 4.388 & $0.66(0.05)$ \\
\hline
\end{tabular}
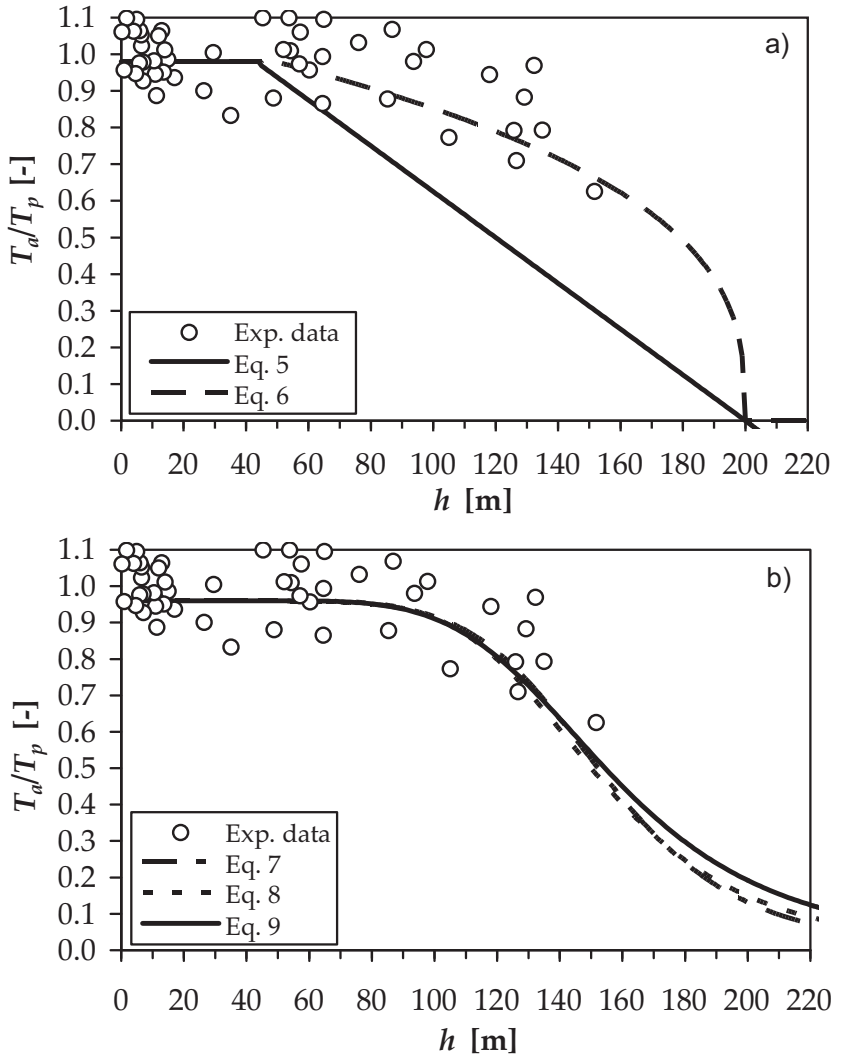

Fig. 8. (a and b) Experimental values of relative transpiration, $T_{a} T_{p}{ }^{-1}$, as a function of soil matric potential, $h$, and fitted water stress models (Eqs. (5)-(9)).

characterized by high water retentivity; (iii) the distances between the plants allow a large soil volume for root absorption.

Accounting for the similar statistical significance of the examined non linear models (Eqs. (7)-(9)), the one requiring the knowledge of a single parameter should be preferred (Eq. (7)). However, further investigations aimed to explore a more extent range of $T_{a} T_{p}{ }^{-1}$ values could allow a better modelling of the stress function under higher water stress levels.

The values of the stress coefficient $\alpha$ in Eq. (10) were determined considering, as indicators, both the measured PLWP and MSWP values, normalized respect of their domain limits. On the other hand the values of $D_{\text {rel }}$ were obtained using Eq. (11), considering $\theta^{*}=0.16 \mathrm{~cm}^{3} \mathrm{~cm}^{-3}\left(D_{\text {rel }}=0\right)$ and $\theta_{\min }=0.11 \mathrm{~cm}^{3} \mathrm{~cm}^{-3}\left(D_{\text {rel }}=1\right)$, as previously discussed.

Fig. 9a and b shows $\alpha, D_{\text {rel }}$ data pairs experimentally determined, the fitted water stress model, as well as the values of the model parameter $f_{s}$.

As can be observed in Fig. 9 the shape of the represented model is still convex, as consequence of $f_{S}>0$ for both cases. Despite the similar RMSE values, the slightly higher dispersion visible when the MSWPs are considered is a consequence of the sensitivity of the measurements from the variation of the environmental variables.
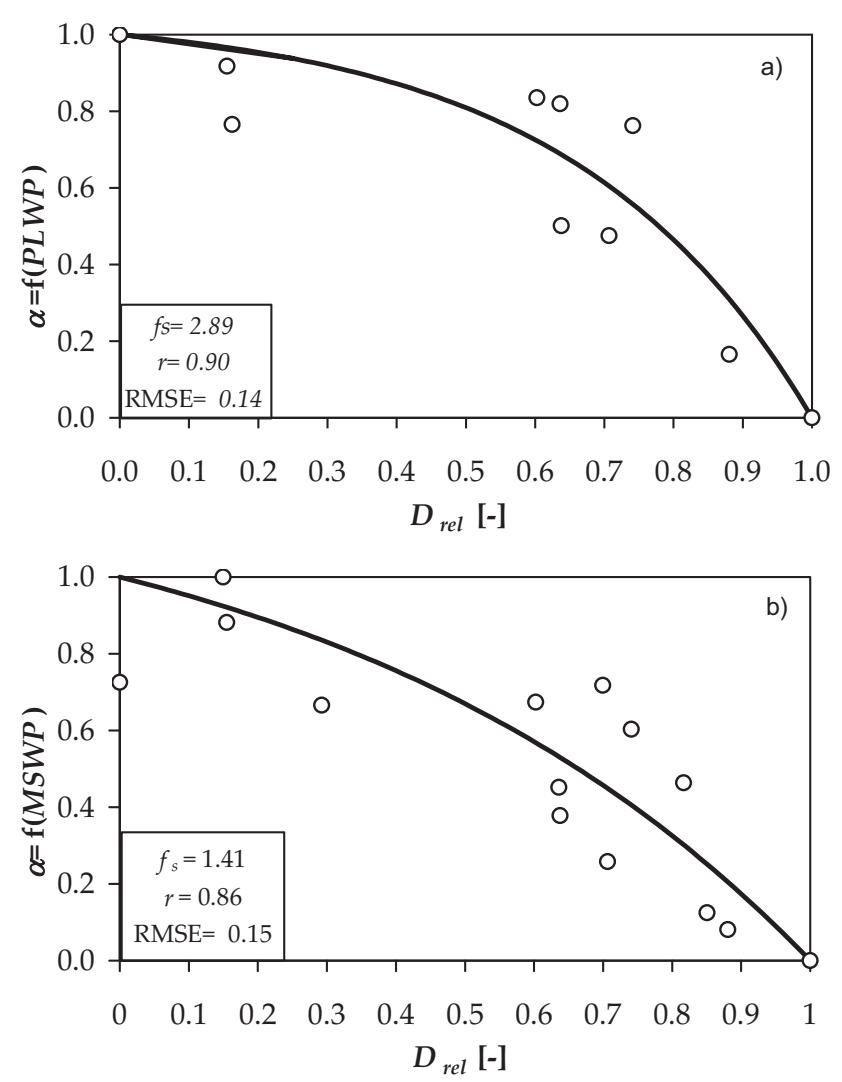

Fig. 9. (a-b) Experimental values of the stress coefficient, $\alpha$, as a function of relative depletion, $D_{\text {rel }}$, and fitted water stress models (Eq. (10)).

Whatever water stress model is considered therefore, for the examined crop, the shape of the stress function is always convex.

\section{Conclusions}

Critical thresholds of soil water status identifying olive crop response to water stress were determined and the performance of existing models representing the stress function analyzed. The experiments evidenced in particular a first critical soil water content $\theta^{*}=0.16 \mathrm{~cm}^{3} \mathrm{~cm}^{-3}$, corresponding to a soil matric potential of about $40 \mathrm{~m}$. This critical soil water content separates two different plant behaviors: $\theta>\theta^{*}$, where the absence of water stress was detected and actual transpiration resulted constant and approximately equal to $2 \mathrm{~mm} \mathrm{~d}^{-1} ; \theta<\theta^{*}$, where crop water stress increases at decreasing $\theta$. On the other side, the most extreme crop water stress was recognized when soil water content was about $0.11 \mathrm{~cm}^{3} \mathrm{~cm}^{-3}$, and soil matric potential of about $200 \mathrm{~m}$. Under this last condition predawn leaf and midday steam water potential resulted equal to 2.2 and $3.7 \mathrm{MPa}$ respectively.

With the exception of the Feddes linear model, for which it is not possible to take into account the shape of the stress function, 
all the other investigated models showed a good agreement with the experimental data.

Non-linear models, in fact, better reproduce the initial phase of the transpiration reduction process, showing that for olive groves the stress function has a convex shape, for which the reduction of actual transpiration is significant only under extreme water stress conditions. Unfortunately, the absence of relative transpiration lower than those observed in the field, did not allow to choose which model can adequately represent the shape of the stress function under very low soil water contents.

\section{Author's contribution}

Contribution to the paper has to be divided as following: field data collection and data processing were cared by G. Rallo. Set-up of research, discussion of results and final revision of the text have to be equally shared between the Authors.

\section{Acknowledgements}

Research was carried out within the project PRIN 2008 (Provenzano), co-financed by Ministero dell'Istruzione, dell'Università e della Ricerca (MIUR) and Università degli Studi di Palermo.

We would like to thank Prof. Carmelo Agnese for his contribution on the discussion of the results.

\section{References}

Ahuja, L.R., Reddy, V.R., Saseendran, S.A., Yu, Q., 2008. Response of Crops to Limited Water: Understanding and Modeling Water Stress Effects on Plant Growth Processes. Complete Book. ASA, CSSSA and SSSA, Madison, Wisconsin, 436 p.

Allen, R.G., Walter, I.A., Elliot, R.L., Howell, T.A., Itenfisu, D., Jensen, M.E., Snyder, R., 2005. The ASCE Standardized Reference Evapotranspiration Equation. ASCE and American Society of Civil Engineers, ISBN 078440805X.

Begg, J.E., Turner, N.C., 1970. Water potential gradients in field tobacco. Plant Physiology 46, 343-346.

Berenguer, M.J., Vossen, P.M., Grattan, S.R., Connell, J.H., Polito, V.S., 2006. Tree irrigation levels for optimum chemical and sensory properties of olive oil. Horticultural Science 41, 427-432.

Berni, J.A.J., Zarco-Tejada, P.J., Sepulcre-Cantó, G., Fereres, E., Villalobos, F., 2009. Mapping canopy conductance and CWSI in olive orchards using high resolution thermal remote sensing imagery. Remote Sensing of Environment 113, 11.

Burke, W., Gabriels, D., Bouma, J., 1986. Soil Structure Assessment. Balkema, Rotterdam, The Netherlands.

Cammalleri, C., Anderson, M.C., Ciraolo, G., D’Urso, G., Kustas, W.P., La Loggia, G., Minacapilli, M., 2010b. The impact of in-canopy wind profile formulations on heat flux estimation in an open orchard using the remote sensing-based twosource model. Hydrology and Earth System Sciences 14 (12), 2643-2659.

Cammalleri, C., Agnese, C., Ciraolo, G., Minacapilli, M., Provenzano, G., Rallo, G., 2010a. Actual evapotranspiration assessment by means of a coupled energy/hydrologic balance model: validation over an olive grove by means of scintillometry and measurements of soil water contents. Journal of Hydrology $392(1-2), 70-82$.

Caruso, G., Gucci, R., Rapoport, H.F., 2011. Deficit irrigation effects on yield components of olive trees during the onset of fruit production. Acta Horticulturae (ISHS) 889, 291-296

D’Andria, R., Lavini, A., Morelli, G., Patumi, M., Terenziani, S., Calandrelli, D., Fragnito, F., 2004. Effect of water regime on five pickling and double aptitude olive cultivars (Olea europaea L.). Journal of Horticultural Science \& Biotechnology 78 (1), 15-23.

Dane, J.H., Hopman, J.W., 2002. Water retention and storage. In: Dane, J.H., Topp, G.C. (Eds.), Methods of Soil Analysis: Part 4-Physical methods. SSSA Book Ser. 5. SSSA, Madison.

Dirksen, C., Kool, J.B., Koorevaar, P., Van Genuchten, M.T., 1993. HYSWASOR-simulation model of hysteretic water and solute transport in the root zone. In: Russo, D., Dagan, G. (Eds.), Water Flow and Solute Transport in Soils. Springer Verlag, New York, pp. 99-122.

Ewers, B.E., Oren, R., 2000. Analysis of assumptions and errors in the calculation of stomatal conductance from sap flux measurements. Tree Physiology 20, 579-590.
Feddes, R.A., Kowalik, P.J., Zaradny, H., 1978. Simulation of Field Water Use and Crop Yield. Simulation Monographs. Pudoc, Wageningen, 189 p., ISBN 9002200676, 9789002200670.

Fernández, J.E., Moreno, F., 1999. Water use by olive tree. Journal of Crop Production $2,101-162$.

Fernández, J.E., Díaz-Espejo, A., Infante, J.M., Duran, P., Palomo, M.J., Chamorro, V., Girón, I.F., Villagarcía, L., 2006. Water relations and gas exchange in olive trees under regulated deficit and partial root zone drying. Plant and Soil 284, 273-291.

Granier, A., 1987. Evaluation of transpiration in a Douglas-fir stand by means of sap flow measurements. Tree Physiology 3, 309-320.

Guswa, A.J., Celia, M.A., Rodriguez-Iturbe, I., 2004. Effect of vertical resolution on predictions of transpiration in water-limited ecosystems. Advances in Water Resources 27, 467-480.

Homaee, M., 1999. Root water uptake under non-uniform transient salinity and water stress. Ph.D. dissertation. Wageningen Agric. Univ., Wageningen, The Netherlands, $173 \mathrm{pp}$.

Jarvis, P.G., Mc Naughton, K.G., 1986. Stomata control of transpiration: scaling up from leaf to region. Advances in Ecological Research 15, 1-49.

Larcher, W., 1995. Physiological Plant Ecology. Springer-Verlag, Berlin, 488 p.

Minacapilli, M., Iovino, M., D’Urso, G., 2008. A distributed agro-hydrological mode for irrigation water demand assessment. Agricultural Water Management 95 (2), 123-132.

Minacapilli, M., Agnese, C., Blanda, F., Cammalleri, C., Ciraolo, G., D’Urso, G., Iovino M., Pumo, D., Provenzano, G., Rallo, G., 2009. Estimation of Mediterranean crops evapotranspiration by means of remote-sensing based models. Hydrology and Earth System Sciences 13, 1061-1074.

Moriana, A., Girón, I.F., Martín-Palomo, M.J., Conejero, W., Ortuño, M.F., Torrecillas, A., Moreno, F., 2010. New approach for olive trees irrigation scheduling using trunk diameter sensors. Agricultural Water Management 97 (November (11)), 1822-1828, http://dx.doi.org/10.1016/j.agwat.2010.06.022, ISSN: 0378-3774.

Newman, E.I., 1966. A method of estimating the total length of root in a sample. Journal of Applied Ecology 3, 139-145.

Patumi, M., D’Andria, R., Fontanazza, G., Morelli, G., Giorio, P., Sorrentino, G., 1999 Yield and quality traits of three intensively trained olive trees cv. under different irrigation regimes. Journal of Horticultural Science \& Biotechnology 74, 729-737.

Patumi, M., D’Andria, R., Marsilio, V., Fontanazza, G., Morelli, G., Lanza, B., 2002. Olive and Olive oil quality after intensive monocone olive growing (Olea europaea L., cv. Kalamata) in different irrigation regimes. Food Chemistry 77, 27-34.

Perrier, A., 1975. Etude de l'evapotranspiration dans les condition naturelles. I. Evaporation et bilan d'energie des surfaces naturelles. Annals of Agronomy 26, 1-18.

Personne, E., Perrier, A., Tuzet, A., 2003. Simulating water uptake in the root zone with a microscopic-scale model of root extraction. Agronomie 23 $153-168$

Raes, D., 2008. Deficit irrigation strategies via crop water productivity modelling: Field research of quinoa in the Bolivian altiplano. PhD thesis diss., Katholieke Universiteit Leuven. 237 p.

Rallo, G., Agnese, C., Minacapilli, M., Provenzano, G., 2012. Comparison of SWAP and FAO agro-hydrological models to schedule irrigation of wine grape. Journal of Irrigation and Drainage Engineering 138 (7), 581-591.

Rousseaux, M.C., Figuerola, P.I., Correa-Tedesco, G., Searles, P.S., 2009. Seasonal variations in sap flow and soil evaporation in an olive (Olea europaea, L.) grove under two irrigation regimes in an arid region of Argentina. Agricultural Water Management 96, 1037-1044.

Scholander, R.R., Hammel, H.T., Bradstreet, E.D., Hemmiegsen, E.A., 1965. Sap pressure in vascular plants. Science $148,339-346$.

Skaggs, T.H., van Genuchten, M.T., Shouse, P.J., Poss, J.A., 2006. Macroscopic approaches to root water uptake as a function of water and salinity stress. Agricultural Water Management 86, 140-149.

Steduto, P., Hsiao, T.C., Raes, D., Fereres, E., 2009. AquaCrop. The FAO crop model to simulate yield response to water. Reference Manual.

Tognetti, R., d'Andria, R., Morelli, G., Calandrelli, D., Fragnito, F., 2004. Irrigation effects on daily and seasonal variations of trunk sap flow and leaf water relations in olive trees. Plant and Soil 263 (1-2), 249-264.

Turner, M.T., Jarvis, G.P., 1982. Measurement of plant water status by the pressure chamber technique. Irrigation Science 9, 289-308.

van Genuchten, M.T., 1980. A closed-form equation for predicting the hydraulic conductivity of unsaturated soils. Soil Science Society of America Journal 44, 892-898.

van Genuchten, M.T., 1987. A numerical model for water and solute movement in and below the root zone. Reserch Report, US Salinity Lab., Riverside, CA.

van Genuchten, M.T., Leij, F.J., Yates, S.R., 1992. The RETC code for quantifying the hydraulic functions of unsaturated soils. Project summary, EPA'S Robert S. Kerr Environmental Research Lab., Ada, OK, USA.

Xiloyannis, C., Dichio, B., Nuzzo, V., Celano, G., 1999. Defence strategies of olive against water stress. Acta Horticulturae 474, 423-426.

Xiloyannis, C., Montanaro, G., Dichio, B., 2012. Irrigation in Mediterranean Fruit Tree Orchards. Irrigation Systems and Practices in Challenging Environments. In: Teang Shui Lee (Ed.), ISBN 978-953-51-0420-9. 